\title{
Time AND Fuel Consumption in Tractors
}

\author{
Mursec, B.; JANZEKOVIC, M.; STAJNKO, D. \& Vindis, P.
}

Abstract: Three agricultural implements (soil preparation machine, disk harrow and circular self-cleaning harrow) were used in four repetitions. The surface area of the field was $19530 \mathrm{~m}^{2}$ and it was divided into twelve plots of $1627,5 \mathrm{~m}^{2}$ each. The test was aimed at proving that time and fuel and, consequently, money can be saved, if new agricultural machinery is used. In the fuel consumption statistically significant differences occurred between the disk harrow and the soil preparation machine and between disk harrow and circular self-cleaning harrow; there were no statistical differences between circular self-cleaning harrow and soil preparation machine. It was proved that the highest consumption occurs when using disk harrow $(20,15 \mathrm{l} / \mathrm{ha})$ and the least fuel consumption when using circular self-cleaning harrow (11,05 l/ha. Least time was used with modern circular self-cleaning harrow (93,16 min./ha) and most with disk harrow (208,07 min./ha).

Key words: soil preparation machine, time consumption, fuel consumption, circular self-cleaning harrow
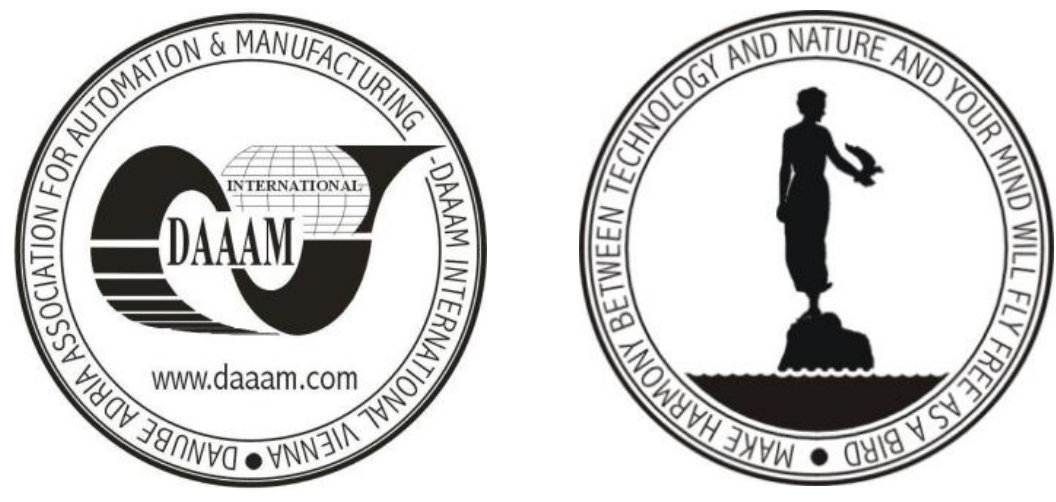

Authors' data: Assoc. Prof. Mursec, B[ogomir]; Assist. Prof. Janzekovic, M[arjan]*; Assoc. Prof. Stajnko, D[enis]; Dr. Vindis, P[eter], University of Maribor, Faculty of Agriculture and Life Sciences, Pivola 10, 2311, Hoce, Slovenia, bogomir.mursec@uni-mb.si, marjan.janzekovic@uni-mb.si, denis.stajnko@unimb.si, peter.vindis@uni-mb.si

This Publication has to be referred as: Mursec, B[ogomir]; Janzekovic, M[arjan]; Stajnko, D[enis] \& Vindis, P[eter] (2011). Time and Fuel Consumption in Tractors, Chapter 07 in DAAAM International Scientific Book 2011, pp. 087-094, B. Katalinic (Ed.), Published by DAAAM International, ISBN 978-3-901509-84-1, ISSN 17269687, Vienna, Austria

DOI: $10.2507 /$ daaam.scibook.2011.07 
Mursec, B.; Janzekovic, M.; Stajnko, D.; \& Vindis, P.: Time and Fuel Consumption...

\section{Introduction}

The aim of the study is finding which agricultural implement uses the least time and which of the three soil preparation implements (soil preparation machine, disk harrow and circular self-cleaning harrow) requires lest fuel on the previously ploughed field. It was interesting to know whether newer agricultural machinery can contribute to time and money saving (Rozman et al., 2006).

In addition to conventional machines for soil preparation (disk harrows, soil preparation machines), lately the circular self-cleaning harrows, which are expensive and pose high demands on maintenance, have been frequently used (Mursec et al. 2006).

The soil preparation machines are supposed to crush the furrow slices and to level and break up the soil in the smallest possible number of passages (Voca et al. 2009). Taking into account the soil structure and the weather conditions the soil must be best prepared for sowing and/or planting after cultivation with soil preparation machines (Oslaj et al. 2010).

\section{Material and methods}

The filed was measured by the internet application Gerkviewer on the pages of the Agency for agricultural markets and landscape and area development. After measuring the field was divided into 12 identical plots (Stajnko et al., 2009). The surface area of the field was $19530 \mathrm{~m}^{2}$ and that of the individual plots $1627,5 \mathrm{~m}^{2}$. Figure 1 shows the start of experiment.

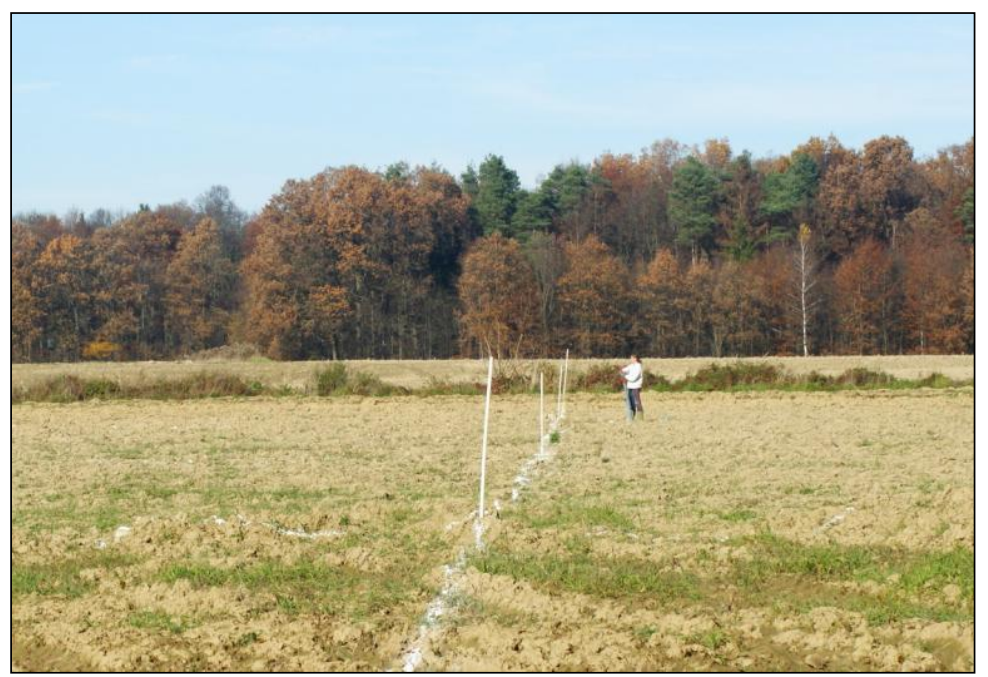

Fig. 1. Start of experiment

The plots were divided by means of tape measure, marking stakes, rope and line (Fig. 2). Staking out of the field started at the north. First, the outer edge was staked out in the clockwise direction. In order to verify the borders a rope stretched between the extreme points north-south and east-west was used in addition to the tape measure. At the connection points white marking stakes were driven, then the borders along the rope were additionally marked with lime (Guzelj, 2011). 


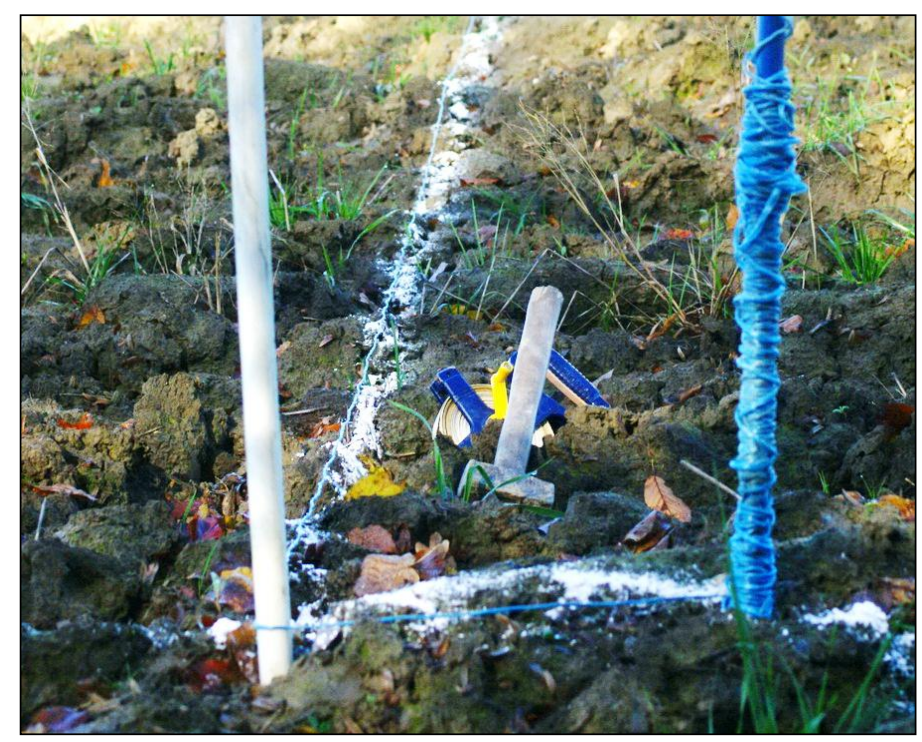

Fig. 2. Plot marking

The fuel consumption was measured by a laboratory measuring cylinder (Fig. 3 ). For each plot the fuel was topped up in the tank prior to beginning of and at the end of cultivation of plot. The reading on the measuring cylinder gave the information about the fuel consumption.

The time was measured by a stop watch from the beginning of the plot marked with lime until the end of cultivation of the individual plot.

The test comprised three treatments with four repetitions.

The tractor New Holland 70-56 DT driven by a four-cylinder water-cooled Iveco engine was used for the test. The working volume of engine is $3613 \mathrm{~cm}^{3}$ and its output $51,5 \mathrm{~kW}$ or $70 \mathrm{HP}$. It has the four-wheel drive. The mass of the empty tractor is $2950 \mathrm{~kg}$.

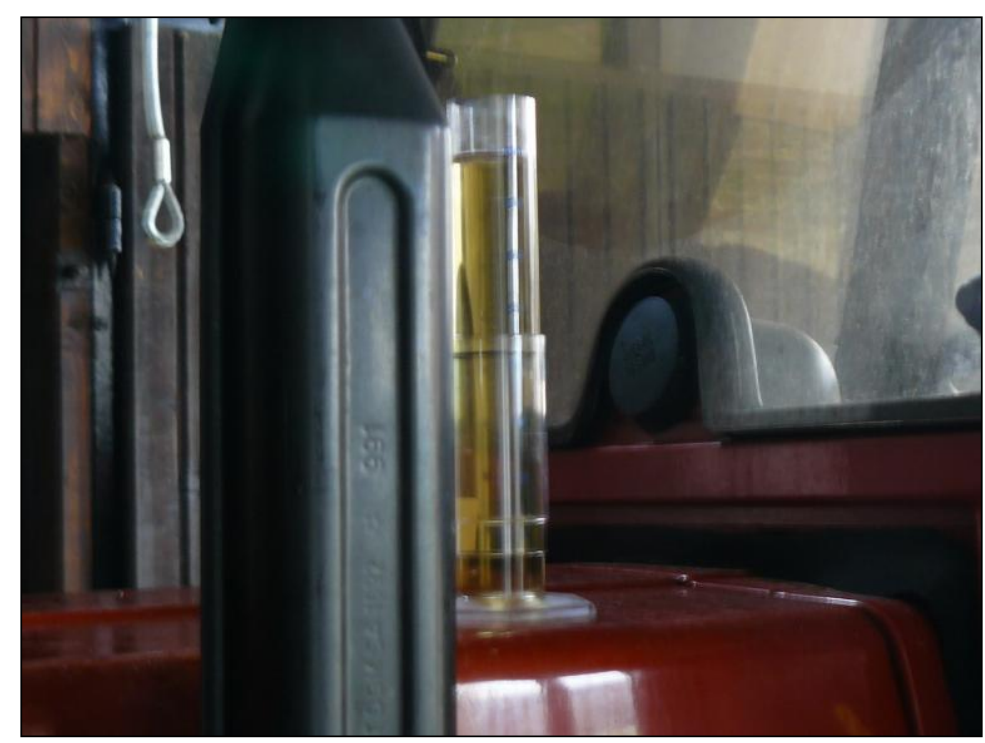

Fig. 3. Laboratory measuring cylinder

Figure 4 shows the circular self-cleaning harrow Emy CL 25 used for the test. This is a harrow of $2,5 \mathrm{~m}$ working width, $824 \mathrm{~kg}$ mass, with 10 pairs of teeth. It is 
Mursec, B.; Janzekovic, M.; Stajnko, D.; \& Vindis, P.: Time and Fuel Consumption... equipped with a Paker roll and is driven through a cardan shaft. During the test the soil was prepared for sowing in one passage at the anticipated speed $6 \mathrm{~km} / \mathrm{h}$.

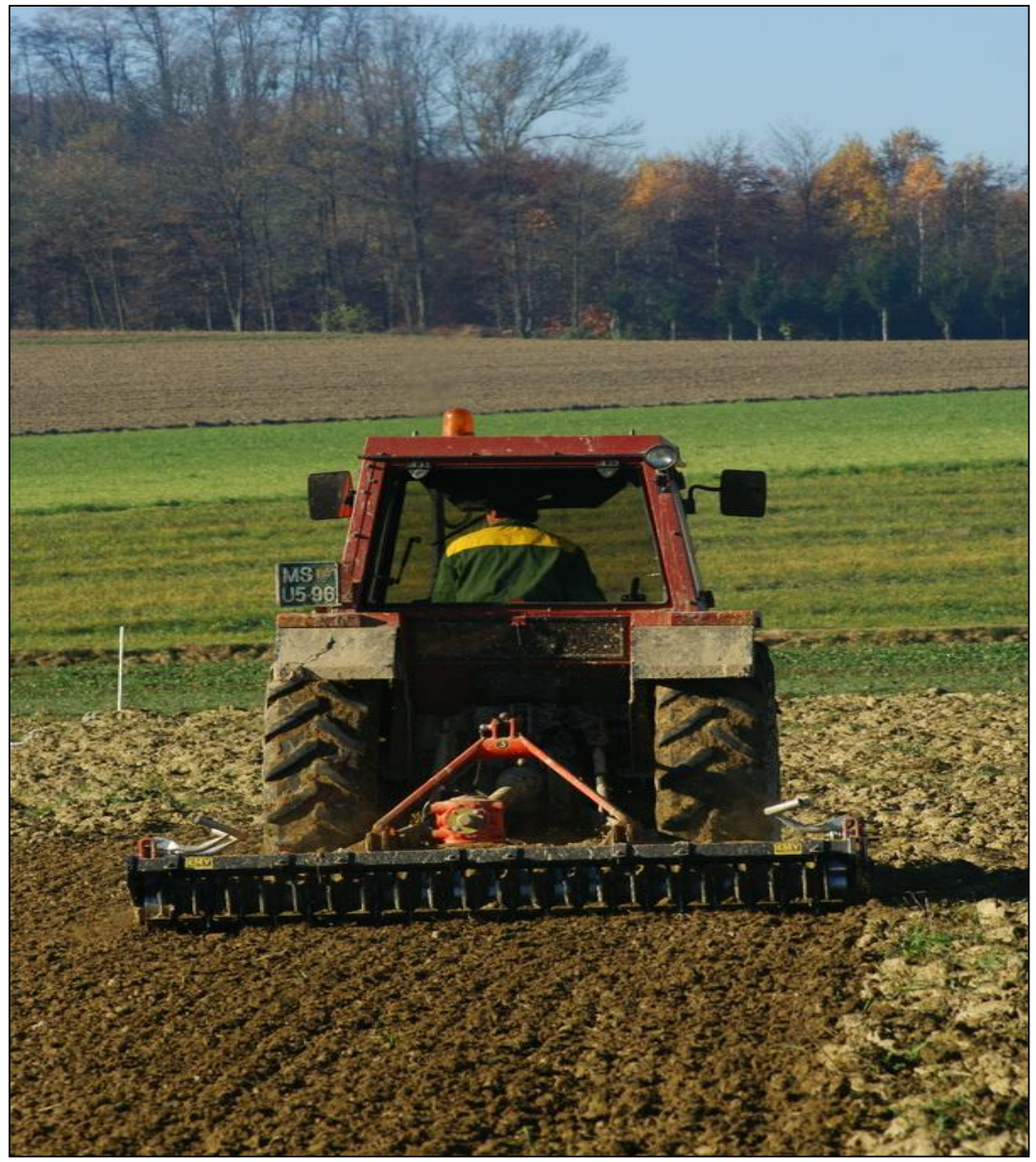

Fig. 4. Circular self-cleaning harrow

Figure 5 shows the soil preparation by circular self-cleaning harrow in one passage.

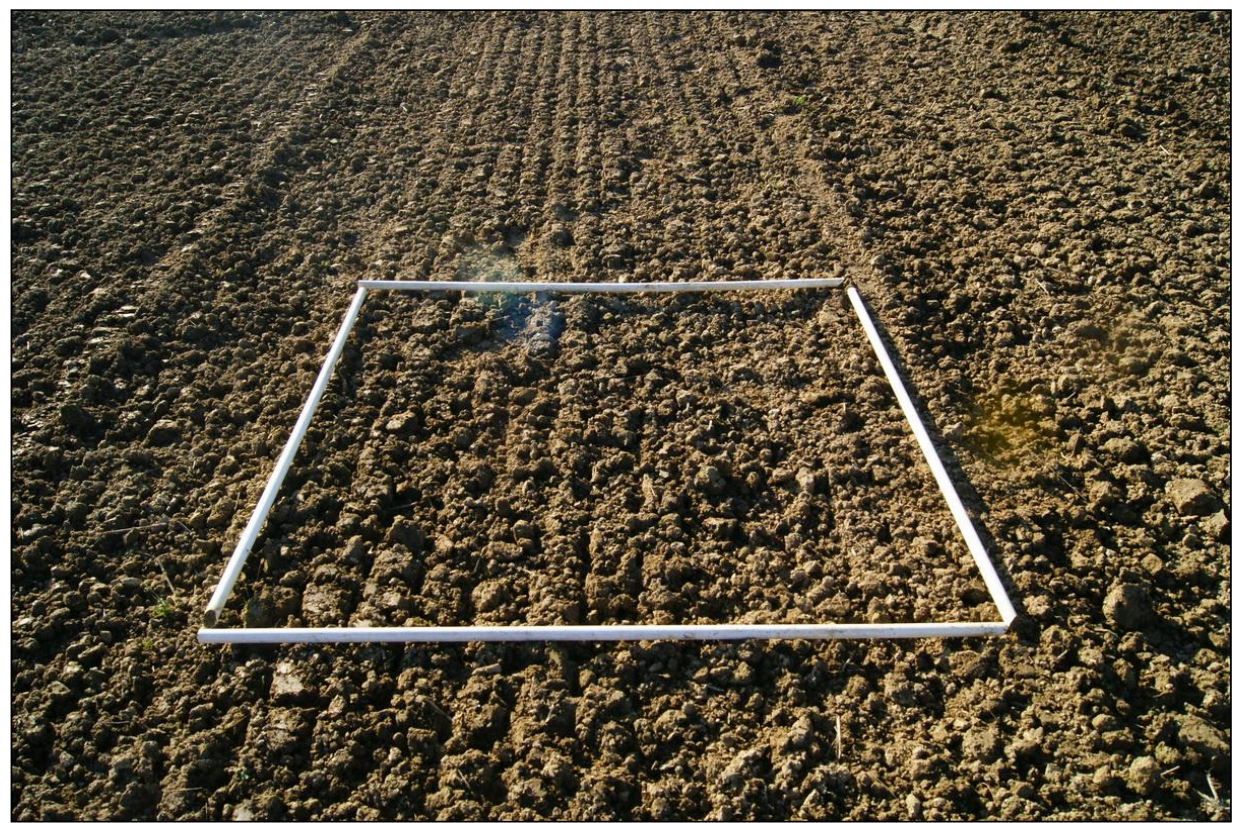

Fig. 5. Soil preparation by circular self-cleaning harrow in one passage 
Figure 6 shows the experiment.

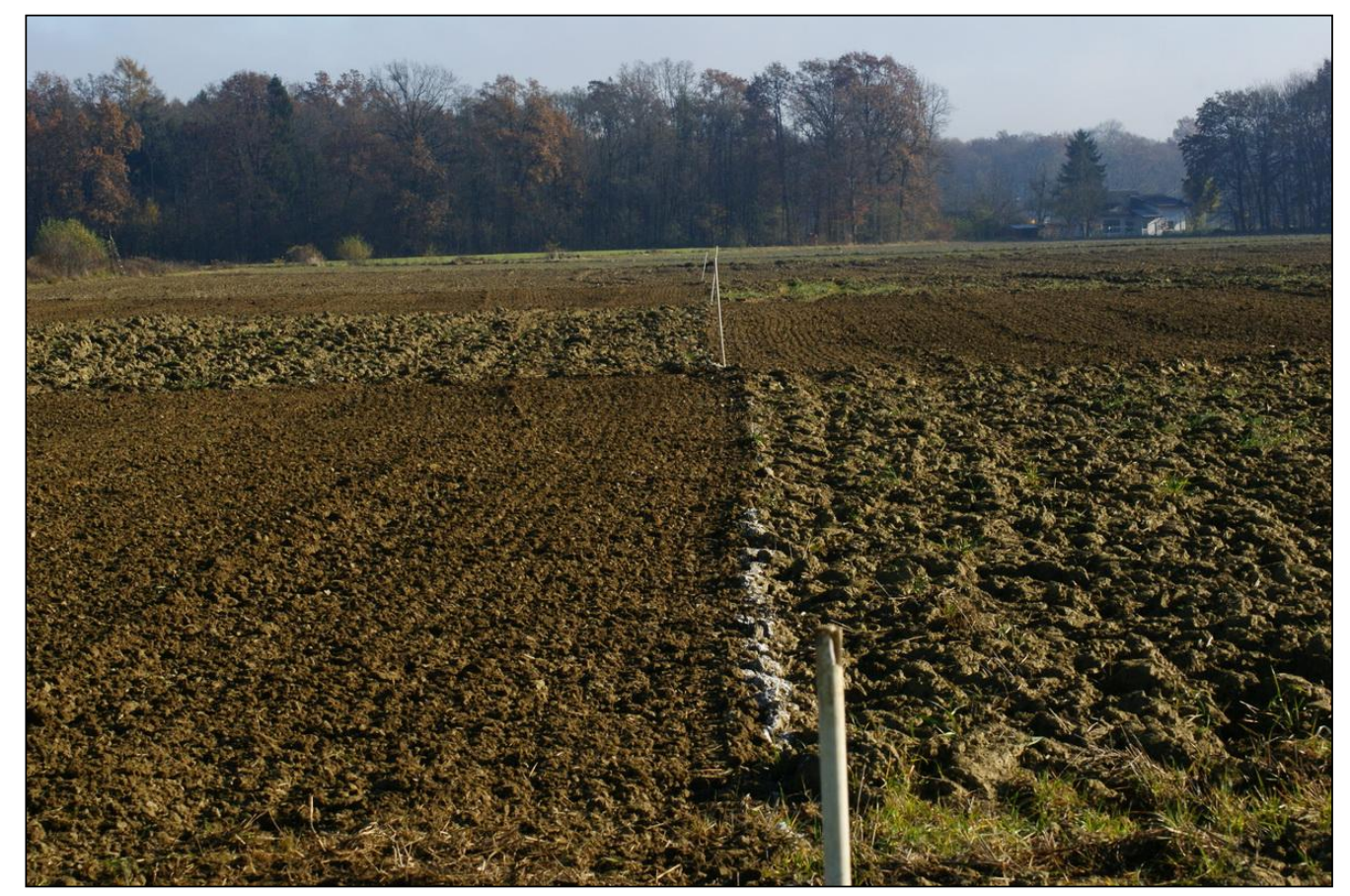

Fig. 6. Experiment

The data were collected and edited in the Excel program. The originally obtained results were converted from values for plots into values per hectare, which allows greater transparency. The statistical package SPSS 17.0 for Windows was used for the statistical analysis. The mean values of the calculated average parameters were compared among the individual treatments by the variance analysis (ANOVA). In order to find out the statistical differences among individual treatments the Tukey HSD test was performed.

The statistically significant differences of the individual parameters among different treatments were in case of $p \leq 0,05$ and statistically insignificant differences were in case of $p \geq 0,05$. Further, statistical differences among individual agricultural implements in the time consumption per unit of surface were determined.

\section{Results with discussion}

Table 1 shows that the circular self-cleaning harrow and the soil preparation machine do not statistically differ in the fuel consumption, whereas the fuel consumption of the disk harrow in comparison with the soil preparation machine and circular self-cleaning harrow does. This proves that the disk harrow as the oldest agricultural implement is most uneconomical in fuel consumption. The other two, more modern, implements consumed less fuel, but it could not be statistically confirmed that the circular self-cleaning harrow used less fuel than the soil preparation machine. 
Mursec, B.; Janzekovic, M.; Stajnko, D.; \& Vindis, P.: Time and Fuel Consumption...

Table 1 shows the differences in fuel consumption among individual implements. First, the values of fuel consumption on plots are indicated, then those values are converted into values per hectare for greater transparency.

\begin{tabular}{|c|c|c|}
\hline Treatment & $\begin{array}{c}\text { Fuel consumption } \\
\text { (1/plot) }\end{array}$ & $\begin{array}{c}\text { Fuel consumption } \\
(1 / \mathrm{ha})\end{array}$ \\
\hline $\begin{array}{c}\text { Circular self } \\
\text { cleaning harrow }\end{array}$ & 1,8 & 11,05 \\
\hline $\begin{array}{c}\text { Soil preparation } \\
\text { machine }\end{array}$ & 1,9 & 12,13 \\
\hline Disk harrow & 3,27 & 20,12 \\
\hline
\end{tabular}

Tab. 1. Average fuel consumption

Figure 7 shows average fuel consumptions, where a considerable difference is obvious between the disk harrow and the other two implements, how much more fuel is consumed for cultivation in the older way, which is a piece of information very much in favour of circular self-cleaning harrow and soil preparation machine which were far more economical. It was not statistically confirmed in case of $p \leq 0,05$ that the circular self-cleaning harrow was more economical, while working with it was more comfortable for the driver, since tractor driving is smoother.

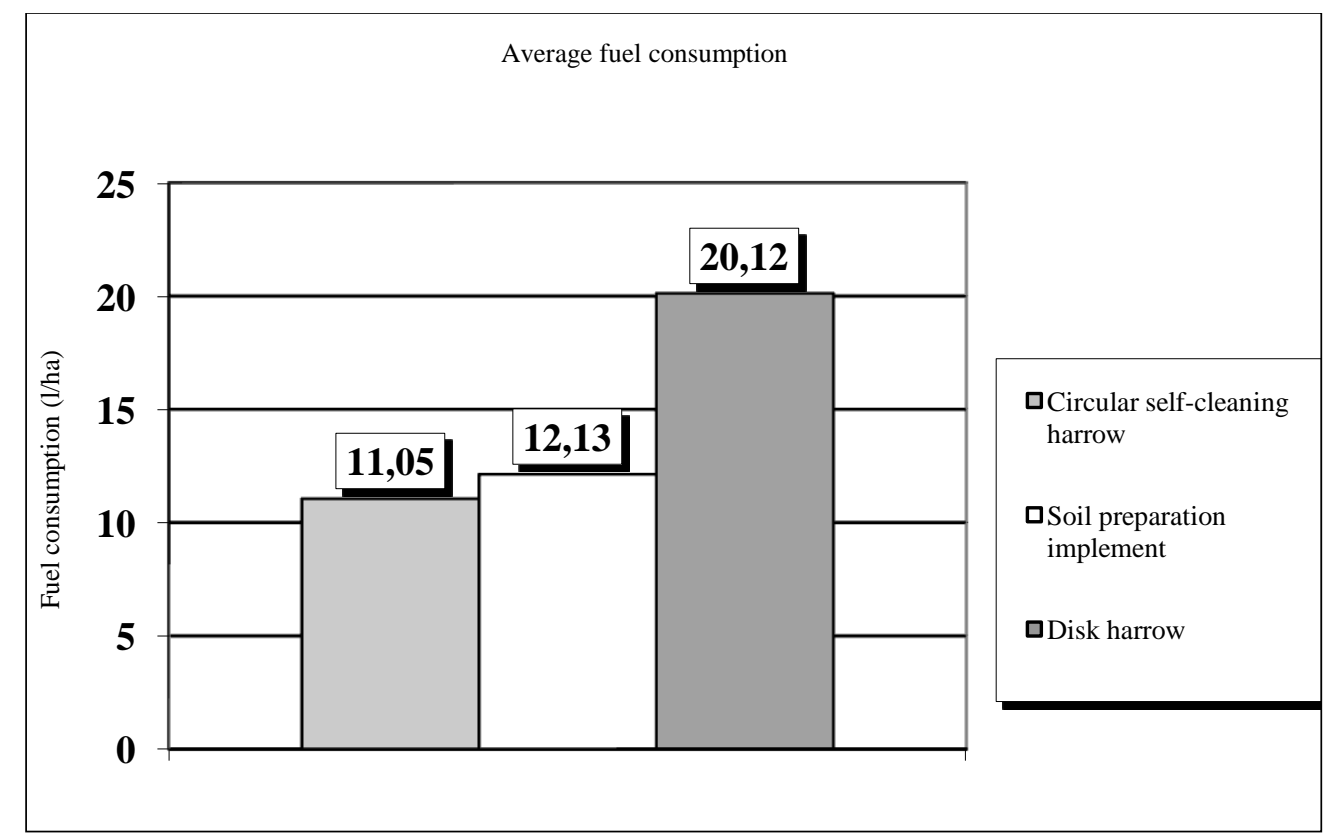

Fig. 7. Average fuel consumption

Concerning the time consumption it was statistically confirmed that the soil was fastest prepared by the circular self-cleaning harrow. The most modern agricultural implement prepared the soil within the shortest time. The oldest agricultural implement used most time. The time sequence was: circular self-cleaning 
harrow, soil preparation machine and, last, the disk harrow. The data were processed according to the Tukey test $(\mathrm{p} \leq 0,05)$.

The target of the test was crumbly soil structure. In order to reach such one passage with the circular self-cleaning harrow, two passages with the soil preparation machine and three passages with the disk harrow were necessary. As a result, this had an effect on the longer time of cultivation with the soil preparation machine and disk harrow.

Table 2 shows time consumptions used for cultivation of plots and those converted into values per hectare. Statistically significant differences occurred in the time consumption among individual agricultural implements. It was anticipated that most time would be used for cultivation with disk harrow, almost one half less time is used for work with the soil preparation machine; the work is performed fastest with circular self-cleaning harrow $(\mathrm{p} \leq 0,05)$.

\begin{tabular}{|c|c|c|}
\hline Treatment & $\begin{array}{c}\text { Time consumption } \\
\text { (min./plot) }\end{array}$ & $\begin{array}{c}\text { Time consumption } \\
\text { (min./ha) }\end{array}$ \\
\hline $\begin{array}{c}\text { Circular self cleaning } \\
\text { harrow }\end{array}$ & 15,16 & 93,16 \\
\hline $\begin{array}{c}\text { Soil preparation } \\
\text { machine }\end{array}$ & 19,16 & 117,77 \\
\hline Disk harrow & 33,86 & 208,07 \\
\hline
\end{tabular}

Tab. 2. Average time consumption

Figure 8 shows the values from table 2, where it can be clearly seen how much time is used for soil preparation with disk harrow in comparison with the soil preparation machine and circular self cleaning harrow.

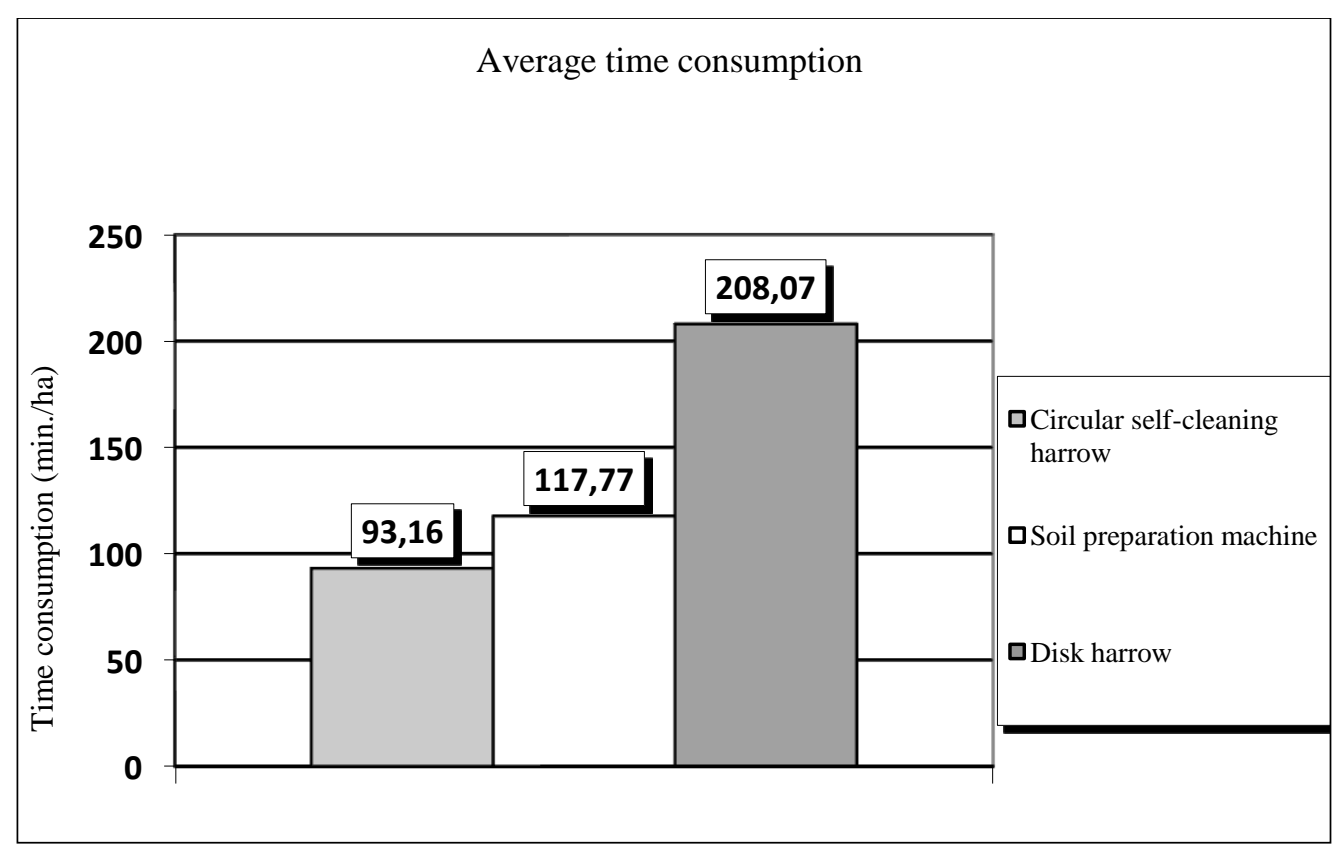

Fig. 8. Average time consumption 
Mursec, B.; Janzekovic, M.; Stajnko, D.; \& Vindis, P.: Time and Fuel Consumption...

\section{Conclusion}

On the basis of the data reached it can be concluded that the advances in agricultural machinery have followed the modern trends and have considerably reduced the environment pollution, by reducing the fuel and time consumption.

Among individual treatments statistically demonstrated differences occurred in the time required for cultivation of one hectare of soil, where all three implements used different values of time.

Statistical data processing showed that the most economical implement was the circular self-cleaning harrow.

During the test various soil preparation machines were compared. Three different agricultural implements (soil preparation machine, disk harrow and circular self cleaning harrow) were used in four repetitions. It was proved that newer agricultural machinery can help save time and fuel and, consequently money.

\section{References}

Guzelj, M. (2011). Comparison of consumption of time and fuel at the use of different machines for soil preparation, Graduate work, University of Maribor, Faculty of Agriculture and Life Sciences, Hoce

Mursec, B.; Janzekovic, M. \& Banaj, Đ. (2006). Investigation of rolling as a secondary soil cultivation process, DAAAM International Scientific Book, Vienna, 431-438, ISSN 1726-9687

Oslaj, M.; Mursec, B. \& Vindis, P. (2010). Biogas production from maize hybrids, Biomass and Bioenergy, Vol. 34, Iss. 11, 1538-1545, ISSN 0961-9534

Rozman, C.; Pazek, K.; Bavec, M.; Bavec, F.; Turk, J. \& Majkovic, D. (2006). The Multi-criteria analysis of spelt food processing alternatives on small organic farms, Journal of Sustainable Agriculture, Vol. 28, Iss. 2, 159-179, ISSN 10440046

Stajnko, D.; Vindis, P. \& Mursec, B. (2009). Reduction of $\mathrm{CO}_{2}$ emission in production of corn in Slovenia. DAAAM International Scientific Book, Vienna, 573-586, ISSN 1726-9687

Voca, N.; Varga, B.; Kricka, T.; Curic, D.; Jurisic, V. \& Matin, A. (2009). Progress in ethanol production from corn kernel by applying cooking pre-treatment, Bioresource Technology, Vol. 100, Iss. 10, 2712-2718, ISSN 0960-8524 